OPEN ACCESS

Edited by:

Stefan Gafner,

American Botanical Council,

United States

Reviewed by:

Jane Manfron,

Universidade Estadual de Ponta

Grossa, Brazil

Kirsten Tripplett,

Traditional Medicinals, Inc.,

United States

*Correspondence:

Feng Wei

weifeng@nifdc.org.cn

Shuangcheng $\mathrm{Ma}$

masc@nifdc.org.cn

Specialty section: This article was submitted to

Ethnopharmacology,

a section of the journal

Frontiers in Pharmacology

Received: 04 August 2020 Accepted: 29 December 2020

Published: 29 January 2021

Citation:

Yu K, Liu W, Zhang N, Cheng X,

Zhou S, Zuo T, Kang S, Wei F and Ma S (2021) A Novel Method to Identify

Three Quality Grades of Herbal Medicine Ophiopogonis Radix by

Microscopic Quantification.

Front. Pharmacol. 11:591310.

doi: 10.3389/fphar.2020.591310

\section{A Novel Method to Identify Three Quality Grades of Herbal Medicine Ophiopogonis Radix by Microscopic Quantification}

\author{
Kunzi Yu ${ }^{1}$, Wei Liu ${ }^{1}$, Nanping Zhang ${ }^{1}$, Xianlong Cheng ${ }^{1}$, Shiyu Zhou ${ }^{2}$, Tiantian Zuo ${ }^{1}$, \\ Shuai Kang ${ }^{1}$, Feng $\mathrm{Wei}^{1 *}$ and Shuangcheng $\mathrm{Ma}^{1 *}$ \\ ${ }^{1}$ Institute for Control of Chinese Traditional Medicine and Ethnic Medicine, National Institutes for Food and Drug Control, Beijing, \\ China, ${ }^{2}$ Chengdu Institute for Food and Drug Control, Chengdu, China
}

Maidong, the root tuber of Ophiopogon japonicus (Thunb.) Ker Gawl., is a commonly used herbal medicine in China. There are three quality grades of Maidong according to traditional opinion and modern research studies: superior quality (Zhe-Maidong), medium quality (Chuan-Maidong), and poorest quality (Chuan-Maidong with paclobutrazol, which is a kind of plant growth regulator). However, no efficient way to distinguish the three quality grades of Maidong exists; thus, the herbal markets and botanical pharmacies are flooded with Chuan-Maidong with paclobutrazol. To ensure the safety and quality of Maidong, a comparative microscopic study was performed on three quality grades of Maidong. The result was to establish a microscopic quantification method based on the area ratio between xylem and pith to distinguish the three quality grades of Maidong. Subsequently, Maidong from regional markets was evaluated by this method. In this study, we developed a novel quantification method to identify the three quality grades of Maidong, which could in turn make efforts on the quality improvement of Maidong. Our study is the first to demonstrate that microscopic technology could be used to distinguish different quality grades of a specific herbal medicine.

Keywords: light microscope microscopy, herbal medicine, botanical identification, quality identification, microscopic quantification, ophiopogonis radix

\section{INTRODUCTION}

Maidong (Ophiopogonis Radix), which is the dried root tuber of Ophiopogon japonicus (Thunb.) Ker Gawl (family: Liliaceae) (the State Pharmacopoeia Committee of China, 2020), is one of the most important herbal medicines and has been used for over 2000 years in China. Maidong has been approved as a functional food ingredient (Lin et al., 2011) and as the main ingredient in patented drugs, such as ShenMai granule and XuanMai Gan Jie capsule/granule (the State Pharmacopoeia Committee of China, 2020). Recent studies have shown that Maidong mainly contains polysaccharides, steroidal saponins, and homoisoflavonoids (Nguyen et al., 2003; Chen et al., 2011; Zhang et al., 2012; Chen et al., 2016). Pharmacological research has revealed the antiinflammatory, antioxidant, immunoregulatory, cardiovascular protective, and venous thrombosis inhibition effects of Maidong (Kou et al., 2005a; Kou et al., 2005b; Xiong et al., 2011; Zhang et al., 2016). Historically, the dried root tubers of Liriope spicata Lour. and L. muscari (Decne.) L. H. Bailey were used as Maidong, which resulted in nomenclatural confusion in herbal markets. In 2010, the 
microscopic characteristics have been described and helped distinguish authentic Maidong from the adulterant species (Mo, 2010). Therefore, distinguishing genuine or counterfeit Maidong is no longer an important issue.

The quality of Maidong is noteworthy and is influenced by at least two factors. The first influencing factor is the cultivation region. There are two main cultivation regions of Maidong in China: Zhejiang province and Sichuan province. Maidong cultivated in Zhejiang province is called Zhe-Maidong; that cultivated in Sichuan province is called Chuan-Maidong. ZheMaidong has been widely recognized as "daodi medicinal material," a quality standard indicating that it has superior quality compared with Chuan-Maidong (Zhao et al., 2012; Li et al., 2016b). Modern research found that ophiopogonin B and ophiopogonin D contents in the tubers of Zhe-Maidong were higher than those in the tubers of Chuan-Maidong (Li et al., 2016a). Moreover, Zhe-Maidong showed higher promoting rates in macrophage phagocytosis and gastrointestinal motility than Chuan-Maidong, suggesting that the former has stronger immunomodulatory activities ( $\mathrm{Lu}$ et al., 2017). The second influencing factor is the cultivation mode. According to our field survey, Zhe-Maidong needs 3-4 years for growth in the field, only a few of Chuan-Maidong is cultivated for 2 years, and most of Chuan-Maidong is cultivated for 1 year only and is overdosed with the plant growth regulator paclobutrazol to increase the yield two to three times. Based on a previous report, a flavonoid and four steroidal saponins were significantly decreased in Maidong after spraying paclobutrazol. In addition, different levels of paclobutrazol residue were detected in Maidong, soil and water samples, and the detection rate of paclobutrazol in Maidong was 100\% (Zhang et al., 2019). The indiscriminate use of paclobutrazol leads to a growing concern about its safety.

When analyzing genetic differences between species, molecular biology techniques mainly rely on gene sequence comparison and calculation of conserved regions on chloroplasts and mitochondria. When analyzing genetic differences within species, biologists generally use gene expression profiles, but the long storage of herbal medicine makes it difficult to obtain plant gene expression profiles, which greatly limits the possibility of using genetic analysis to classify the quality grades of herbal medicine. Moreover, techniques based on chemical component analysis to identify the three quality grades have not been established, and thus no method to distinguish the different quality grades of Maidong exists. Based on this situation, Zhe-Maidong and ChuanMaidong could barely be found in markets and ChuanMaidong with paclobutrazol is rampant in the market, thereby reducing the medicinal quality of Maidong. In addition, the long planting cycle of Zhe-Maidong minimized the farmers' economic interests; superior germplasm resource of Zhe-Maidong is reducing and vanishing gradually (Li et al., 2016b). Therefore, establishing a method to distinguish the three quality grades of Maidong is vital.

Microscopic technology has the advantages of speed, simplicity, reliability, requires small samples amounts, and is low cost. This method is applied in many pharmacopoeias
(Zhao et al., 2006) and has been successfully used to identify herbal medicines and authenticate Chinese prescriptions (Liu et al., 2011; Kang et al., 2012; Xu et al., 2015). Moreover, histological techniques based on microscopic examination have been used to reveal the characteristics of tissue structure and arrangement of cells that could be used as markers for identifying original sources of plant-derived drugs, such as Aloe vera var. chinensis (Shen et al., 2001) and Dendrobium officinale Kimura et Migo (Yu et al., 2017). While microscopic and histological studies in quantitative analysis are limited, they are effective. For example, Wuzhimaotao (Radix Fici Hirtae) was identified by laticifer quantification (Au et al., 2009). However, distinguishing the same herbal medicine from different cultivation locations and with different cultivation modes based on microscopic techniques is not been developed yet, and the histological differences due to plant growth regulators have not been reported completely.

In this study, we established an analytical method to quantify microscopic characteristics; the quantification method was subsequently applied to examine Maidong from different cultivation regions and with different cultivation modes. This study aimed to provide scientific and objective data using microscopic quantification to identify the quality grades of Maidong, which could in turn promote the use of the best herbs and thus ensure the effectiveness and safety of Maidong.

\section{MATERIALS AND METHODS}

\section{Plant Material}

Eighteen batches of Maidong, including four batches of ZheMaidong, four batches of Chuan-Maidong, and ten batches of Chuan-Maidong with paclobutrazol, from the field were used in this study. The details of each sample are presented in Table 1. To validate the method established by this study and evaluate the quality of Maidong in market, twelve batches of Maidong were obtained from herbal markets and botanical pharmacies in different provinces in China (Table 2). All samples were authenticated by Dr Shuai Kang (Institute for Control of Chinese Traditional Medicine and Ethnic Medicine, National Institutes for Food and Drug Control), and the voucher specimen (no. CH-056-100) was deposited in the National Institute for the Control of Pharmaceutical and Biological Products, National Institutes for Food and Drug Control, Beijing, China.

\section{Apparatus}

All transverse sections of the materials were prepared using Leica Jung Biocut 2035 (Leica Instruments, Germany). A light microscope (Olympus BX51, Japan) equipped with an Olympus DP71 digital camera (Olympus, Tokyo, Japan) was used for image acquisition. Images were processed with a Zeiss AX10 equipped with a Zeiss AxioCam ICc five camera and analyzed by ZEN 2.3 lite (Zeiss, Germany). Area was measured in $\mu \mathrm{m}^{2}$.

Liquid chromatography/mass spectrometry (LC/MS) analysis was conducted using Agilent 1200 and Agilent 6410 Triple Quad LC/MS systems (Agilent Technologies, Santa Clara, CA, 
TABLE 1 | Data of the three quality grades of Maidong.

\begin{tabular}{|c|c|c|c|c|c|}
\hline Maidong & Source & Batch no. & Collection area & GPS coordinate & Collection date \\
\hline \multirow[t]{4}{*}{ Zhe-maidong } & Field & $\mathrm{Z1}$ & Hangzhou, Zhejiang & E $118^{\circ} 753^{\prime}$, N $29^{\circ} 124^{\prime}$ & March 2013 \\
\hline & & $\mathrm{Z} 2$ & Cixi, Zhejiang & E $121^{\circ} 279^{\prime}$, N $30^{\circ} 175^{\prime}$ & September 2010 \\
\hline & & $\mathrm{Z3}$ & Cixi, Zhejiang & E $122^{\circ} 563^{\prime}$, N $31^{\circ} 564^{\prime}$ & May 2006 \\
\hline & & Z4 & Cixi, Zhejiang & E $121^{\circ} 751^{\prime}$, N $30^{\circ} 945^{\prime}$ & August 2009 \\
\hline \multirow[t]{4}{*}{ Chuan-maidong } & Field & $\mathrm{C} 1$ & Nanchong, Sichuan & E $105^{\circ} 367^{\prime}$, N $30^{\circ} 575^{\prime}$ & April 2018 \\
\hline & & $\mathrm{C} 2$ & Nanchong, Sichuan & E $105^{\circ} 624^{\prime}$, N $30^{\circ} 863^{\prime}$ & April 2018 \\
\hline & & C3 & Nanchong, Sichuan & E $106^{\circ} 157^{\prime}$, N $31^{\circ} 116^{\prime}$ & April 2018 \\
\hline & & C4 & Nanchong, Sichuan & $\mathrm{E} 105^{\circ} 421^{\prime}, \mathrm{N} 31^{\circ} 254^{\prime}$ & May 2018 \\
\hline \multirow[t]{10}{*}{ Chuan-maidong with paclobutrazol } & Field & CP1 & Mianyang, Sichuan & E $104^{\circ} 561^{\prime}$, N $30^{\circ} 577^{\prime}$ & November 2015 \\
\hline & & CP2 & Mianyang, Sichuan & E $105^{\circ} 241^{\prime}$, N $31^{\circ} 784^{\prime}$ & August 2018 \\
\hline & & CP3 & Mianyang, Sichuan & E $103^{\circ} 875^{\prime}$, N $32^{\circ} 218^{\prime}$ & August 2018 \\
\hline & & CP4 & Mianyang, Sichuan & E $105^{\circ} 116^{\prime}$, N $32^{\circ} 511^{\prime}$ & August 2018 \\
\hline & & CP5 & Mianyang, Sichuan & E $104^{\circ} 335^{\prime}$, N $31^{\circ} 782^{\prime}$ & August 2018 \\
\hline & & CP6 & Mianyang, Sichuan & E $104^{\circ} 951^{\prime}$, N $30^{\circ} 756^{\prime}$ & April 2018 \\
\hline & & CP7 & Mianyang, Sichuan & E $105^{\circ} 223^{\prime}$, N $32^{\circ} 155^{\prime}$ & April 2018 \\
\hline & & CP8 & Mianyang, Sichuan & E $104^{\circ} 596^{\prime}$, N $31^{\circ} 321^{\prime}$ & April 2018 \\
\hline & & CP9 & Mianyang, Sichuan & E $105^{\circ} 332^{\prime}$, N $32^{\circ} 544^{\prime}$ & April 2018 \\
\hline & & CP10 & Mianyang, Sichuan & E $103^{\circ} 651^{\prime}$, N $30^{\circ} 965^{\prime}$ & May 2015 \\
\hline
\end{tabular}

TABLE 2 | Data of Maidong from the herbal markets and botanical pharmacies.

Batch no.

Collection area

\section{MS1}

MS2

MS3

MS4

MS5

MS6

MS7

MS8

MS9

MS10

MS11

MS12

$\begin{array}{ll}\text { Chengdu, Sichuan; herbal market } & \text { May } 2017 \\ \text { Hefei, Anhui; botanical pharmacies } & \text { May } 2017 \\ \text { Shanghai; botanical pharmacies } & \text { May } 2017 \\ \text { Mianyang, Sichuan; herbal market } & \text { May } 2017 \\ \text { Wuhan, Hubei; botanical pharmacies } & \text { June } 2017 \\ \text { Anguo, Hebei; herbal market } & \text { June } 2017 \\ \text { Shijiazhuang, Hebei; botanical pharmacies } & \text { Nov } 2020 \\ \text { Beijing; botanical pharmacies } & \text { Nov 2020 } \\ \text { Bozhou, Anhui; herbal market } & \text { Nov 2020 } \\ \text { Bozhou, Anhui; herbal market } & \text { Nov 2020 } \\ \text { Guangzhou, Guangdong; herbal market } & \text { Nov 2020 } \\ \text { Foshan, Guangdong; botanical pharmacies } & \text { Nov 2020 }\end{array}$

United States). A high-performance liquid chromatography (HPLC) analytical column $(4.6 \times 250 \mathrm{~mm}, 5.0 \mu \mathrm{m}$, ZORBAX SB-C18, Agilent, United States) was used at $40^{\circ} \mathrm{C}$.

\section{Reagents}

Chloral hydrate test solution was prepared using $50 \mathrm{~g}$ of chloral hydrate powder (Sinopharm Chemical Reagent, China), $15 \mathrm{ml}$ of distilled water, and $10 \mathrm{ml}$ of glycerinum (Sinopharm Chemical Reagent, China). Phloroglucinol test solution, which is a classic dye used to stain lignified cell walls red, was prepared using $0.5 \mathrm{~g}$ of phloroglucinol powder (Sinopharm Chemical Reagent, China) and $25 \mathrm{ml}$ of $95 \%$ ethanol (Sinopharm Chemical Reagent, China). Diluted glycerin was prepared using $33 \mathrm{ml}$ of glycerinum and $67 \mathrm{ml}$ of distilled water. After the preparation, the aforementioned three solutions were filtered into dark-colored bottles and kept at room temperature. A paclobutrazol standard was purchased from Aladdin Industrial Corporation (P109932$250 \mathrm{mg}$, Shanghai, China); HPLC-grade acetonitrile were purchased from Sinopharm Chemical Reagent. Pure water was prepared using a Milli-Q water purification system (Millipore, Burlington, MA, United States).

\section{Preparation of Standard and Market Sample Solution for LC/MS Analysis}

The reference compound of paclobutrazol was weighed accurately and dissolved in acetonitrile to produce standard solutions. The samples from herbal markets and botanical pharmacies were powdered, and each powdered sample of $2 \mathrm{~g}$ (accurately weighed) was ultrasonicated with $20 \mathrm{ml}$ of acetonitrile containing $0.1 \%$ formic acid for $30 \mathrm{~min}$. Each solution was centrifuged at $3,000 \mathrm{rpm}$ for $10 \mathrm{~min}$. The supernatant was saved and filtered through a $0.45 \mu \mathrm{m}$ filter for qualitative analysis.

\section{METHOD}

For each batch of root tuber of O. japonicus, four samples were investigated. To investigate the microscopic characteristics of each sample in different section locations, tissues from the middle, upper, and lower sampling sites were sectioned and compared (Figure 1).

Samples were sectioned using Leica Jung Biocut 2035 to $30 \mu \mathrm{m}$ thickness. Slides were prepared by adding one to two drops of chloral hydrate solution, rapidly heating to boiling repeatedly, and cleaning away excess chloral hydrate solution. One drop of phloroglucinol solution and hydrochloric acid stain, which was allowed to sit for $3 \mathrm{~min}$, was used to stain lignified cells, and excess solution on the slide was washed away with diluted glycerin. Thereafter, the slides were sealed with diluted glycerin and observed under a microscope. The xylem and pith area of each sample was measured with ZEN 2.3 lite, and then data were analyzed using Statistical Package for the Social Sciences (SPSS).

The conditions for chromatographic separations were as follows: mobile phase consisted of water containing $0.1 \%$ formic acid and acetonitrile, and the isocratic elution program was $20 \%$ acetonitrile $(20 \mathrm{~min})$. The flow rate was 


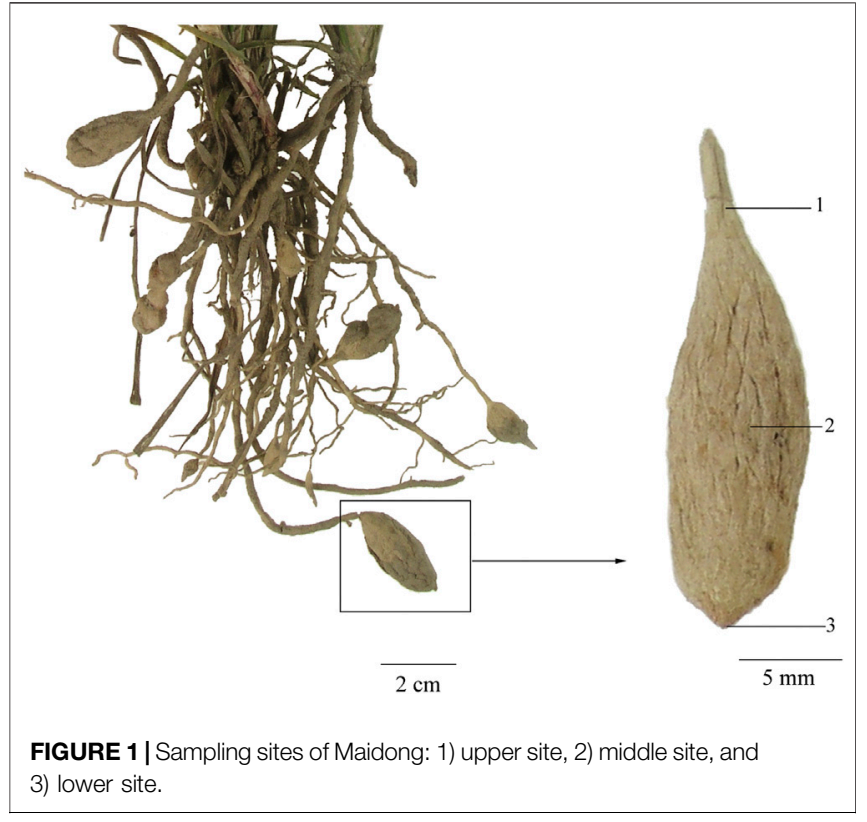

$0.3 \mathrm{ml} / \mathrm{min}$, and the injection volume was $5 \mu \mathrm{l}$. Mass spectra were detected in the positive mode. Moreover, the source parameters were as follows: dry gas $\left(\mathrm{N}_{2}\right)$ temperature $350^{\circ} \mathrm{C}$; flow rate $8 \mathrm{~L} / \mathrm{min}$; sheath gas flow $8 \mathrm{~L} / \mathrm{min}$ with heater at $350^{\circ} \mathrm{C}$; nebulizer pressure $45 \mathrm{psi}$; and capillary voltage $3500 \mathrm{~V}$. The dwell time for each ion pair was $20 \mathrm{~ms}$, and each sample was analyzed in triplicate.

\section{RESULTS}

\section{Testing and Identifying Field Samples}

Transverse section: Velamen consisting of 3-5 layers of lignified cells and cortex broad, showing scattered mucilage cells containing raphides of calcium oxalate, which seldom thickened to $5-10 \mu \mathrm{m}$ in diameter; endodermal cells with evenly thickened and lignified walls, with subrounded cell cavity; and a layer of stone cells lying at the outside of endodermis, the inner and lateral walls thickened, and finely and densely pitted. Stele is relatively small, and 16-22 phloem bundles were noted. Protoxylem stellate and metaxylem linking up in a ring were observed. Pith cells were small, and parenchymatous cells were subrounded. According to Mo (Mo, 2010), thickened raphides of calcium oxalate, subrounded cell cavity of endodermal cells, and number of phloem bundles are the three main characteristics that distinguish genuine from adulterated Maidong (Figure 2).
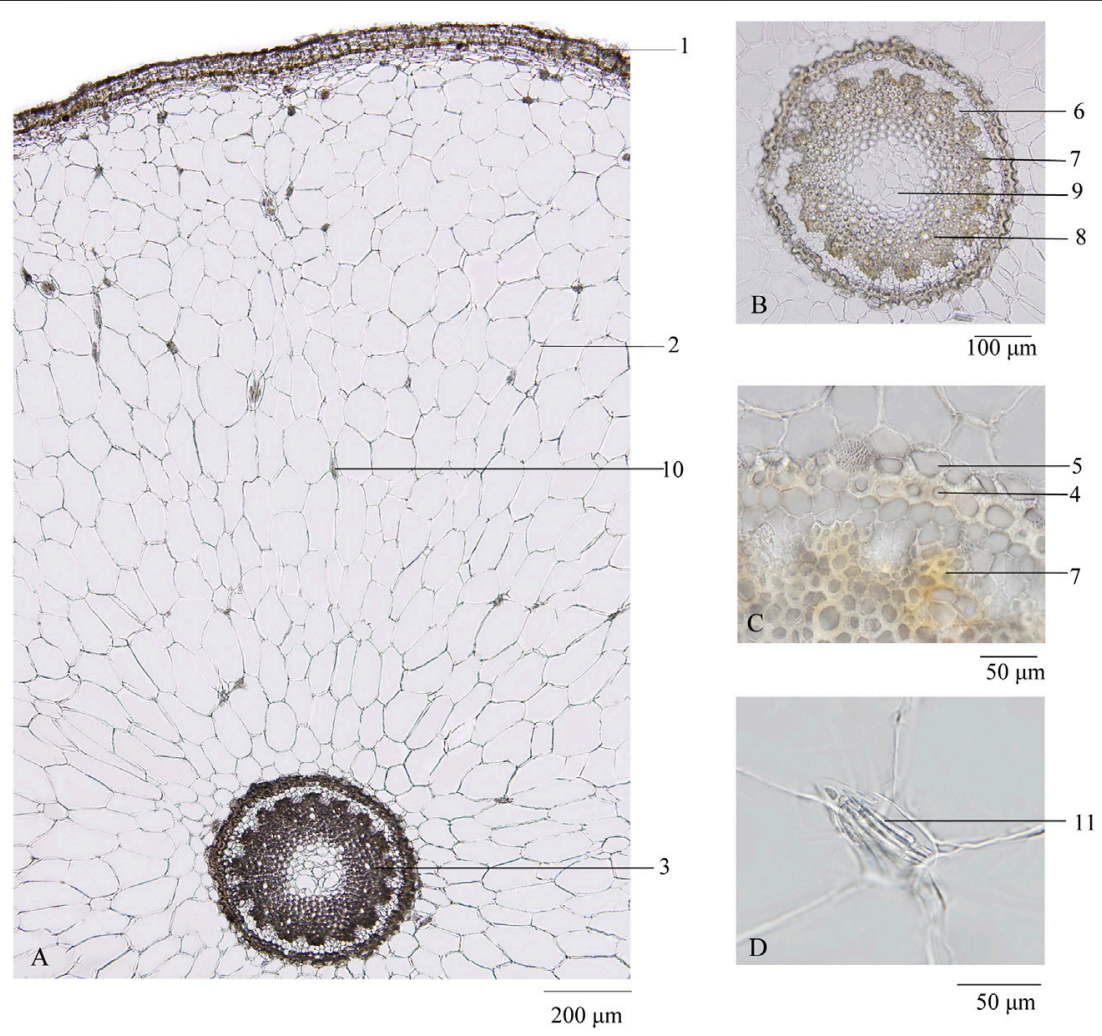

FIGURE 2 | Transverse section of Maidong: (A) root transverse section; (B) stele; (C) endodermis; (D) thickened raphides of calcium oxalate. 1) Velamen, 2) cortex, 3) stele, 4) endodermis, 5) stone cells, 6) phloem, 7) protoxylem, 8) metaxylem, 9) pith, 10) raphides of calcium oxalate, and 11) thickened raphides of calcium oxalate. 

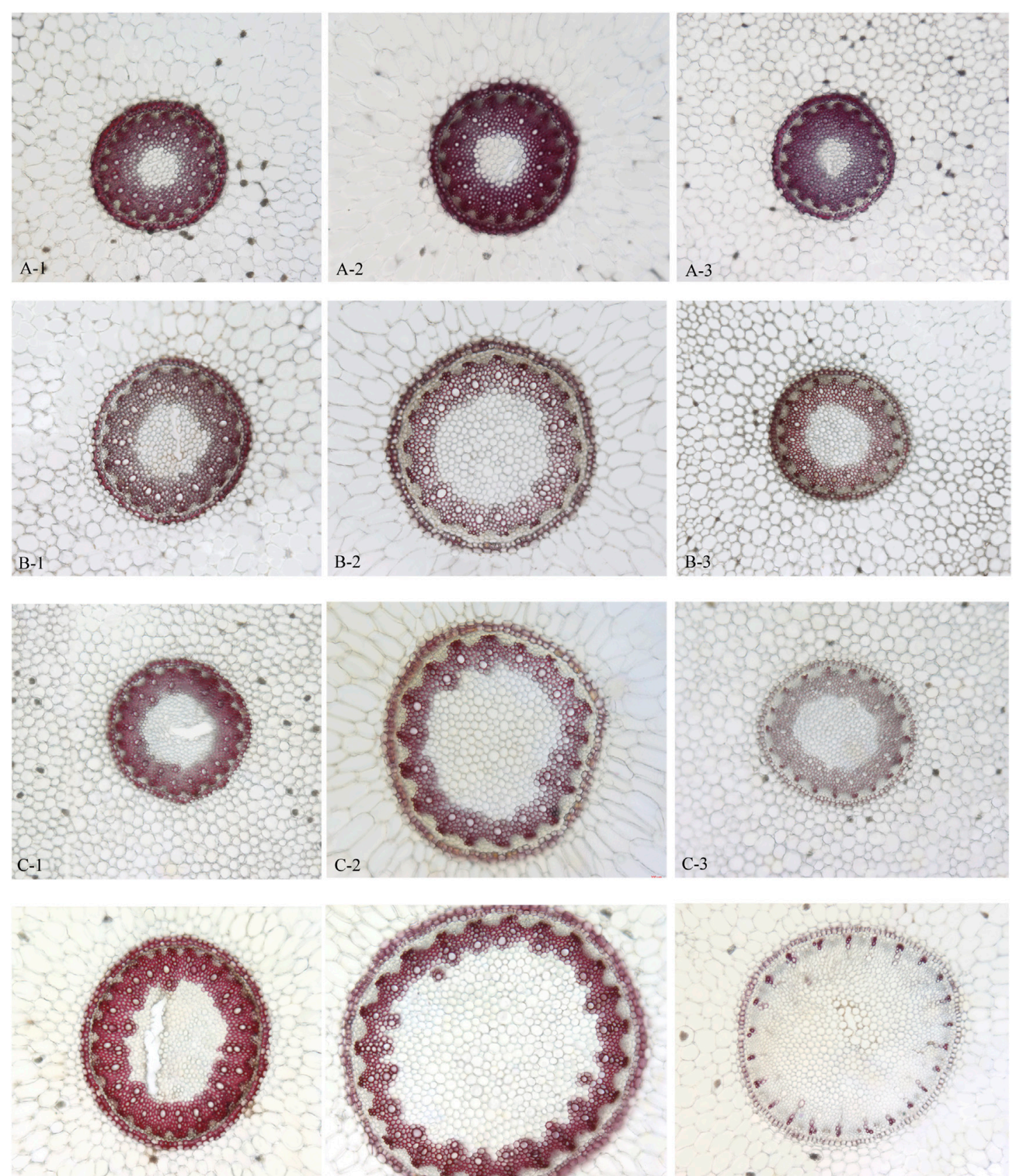

D-1
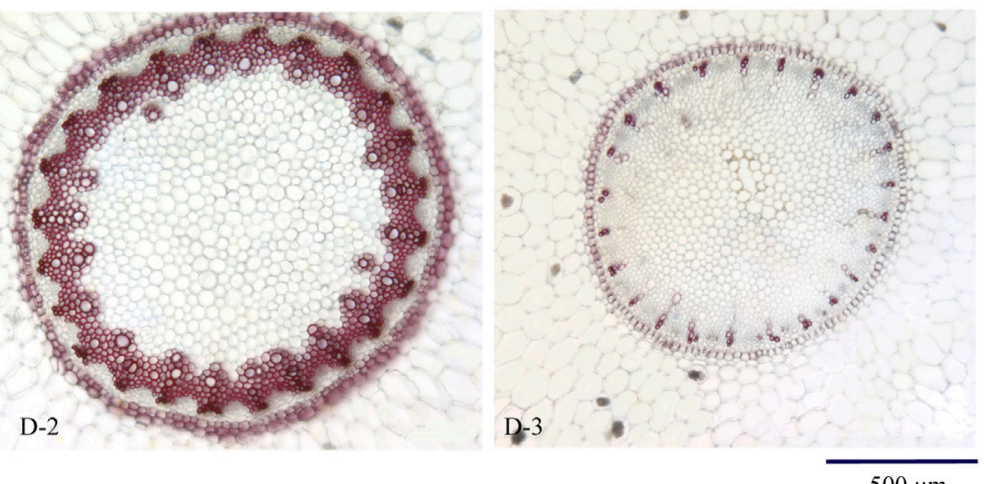

FIGURE 3 | Transverse section of Maidong from different sampling sites: (A) Zhe-Maidong, (B) Chuan-Maidong, and (C,D) Chuan-Maidong with paelobutrazol. 1) Upper site, 2) middle site, and 3) lower site.

The transverse sections of all the samples were investigated to ensure accuracy of the species.

\section{Investigation of Sampling Sites}

To explore the influence of microscopic characteristics by sampling sites, the upper, middle, and lower sites were investigated separately (Figure 1).
Across all samples, the velamen and cortex were stable and showed no difference among the three quality grades of Maidong. Thus, this study focused on the microscopic characteristics of the endodermis and stele.

\section{Zhe-Maidong}

The diameter of stele and pith in the upper and lower sampling sites was smaller than that in the middle sampling sites. 
Microscopic elements including the thickness and lignification of endodermis and stone cells, the shape of protoxylem, and lignification of xylem showed no difference among the upper, lower, and middle sampling sites (Figure 3A, A-1, 2, 3).

\section{Chuan-Maidong}

The diameter of stele and pith in the upper and lower sampling sites was smaller than that in the middle sampling sites. The shape of the protoxylem in the upper and lower sampling sites was clearly distinct; the protoxylem in the upper sampling site was obtusely rounded and that in the lower sampling site showed acute angles. The thickness and lignification of endodermis and stone cells and the lignification of xylem showed no difference among the upper, lower, and middle sampling sites. In addition, the pith area was larger in Chuan-Maidong than in Zhe-Maidong, and the thickness and lignification of endodermis and stone cells were lower in Chuan-Maidong than in Zhe-Maidong (Figure 3B, B-1, 2, 3).

\section{Chuan-Maidong With Paclobutrazol}

The diameter of stele and pith in the upper and lower sampling sites was smaller than that in the middle sampling site. The shape of the protoxylem in the upper and lower sampling sites was clearly distinct. The protoxylem in the upper sampling site was obtusely rounded and that in the lower sampling site showed acute angles (Figure 3C, C-1, 2, 3). Furthermore, the metaxylem was undeveloped and could not link up to a ring in $48 \%$ (19 of 40 ) of the Chuan-Maidong with paclobutrazol (Figure 3D, D-3). The thickness and lignification of endodermis and stone cells and the lignification of xylem in the lower sampling site were much less than those in the upper and middle sampling sites. In addition, only a few stone cells with thickened and lignified cell walls were located outside the endodermis in middle and lower sampling sites in some of the Chuan-Maidong with paclobutrazol samples. The pith area was larger in Chuan-Maidong with paclobutrazol than in ZheMaidong, and the thickness and lignification of endodermis and stone cells in Chuan-Maidong with paclobutrazol were less than those of Zhe-Maidong (Figure 3).

\section{Microscopic Quantification}

The microscopic characteristics of Maidong were influenced by the sampling sites in our study (see Investigation of Sampling Sites section). Thus, in the comparative study among the three quality grades of Maidong, the microscopic characteristics in the middle sampling site were investigated.

As shown in Figures 3A-D (A-2, B-2, C-2, D-2), the pith and xylem area are clearly different among the three quality grades of Maidong. After staining with phloroglucinol test solution, only the xylem was stained red; thus, examining the boundary between xylem and pith/phloem was easy. The actual area of the selected scope was measured using the analysis function of ZEN software (Figure 4).

The pith and xylem areas in the middle sampling site of all samples were measured and calculated (Table 3). The pith area ranged from 24,675 to $188,958 \mu^{2}$ for Zhe-Maidong, 140,699 to $383,775 \mu \mathrm{m}^{2}$ for Chuan-Maidong, and 264,706 to $1,114,243 \mu \mathrm{m}^{2}$
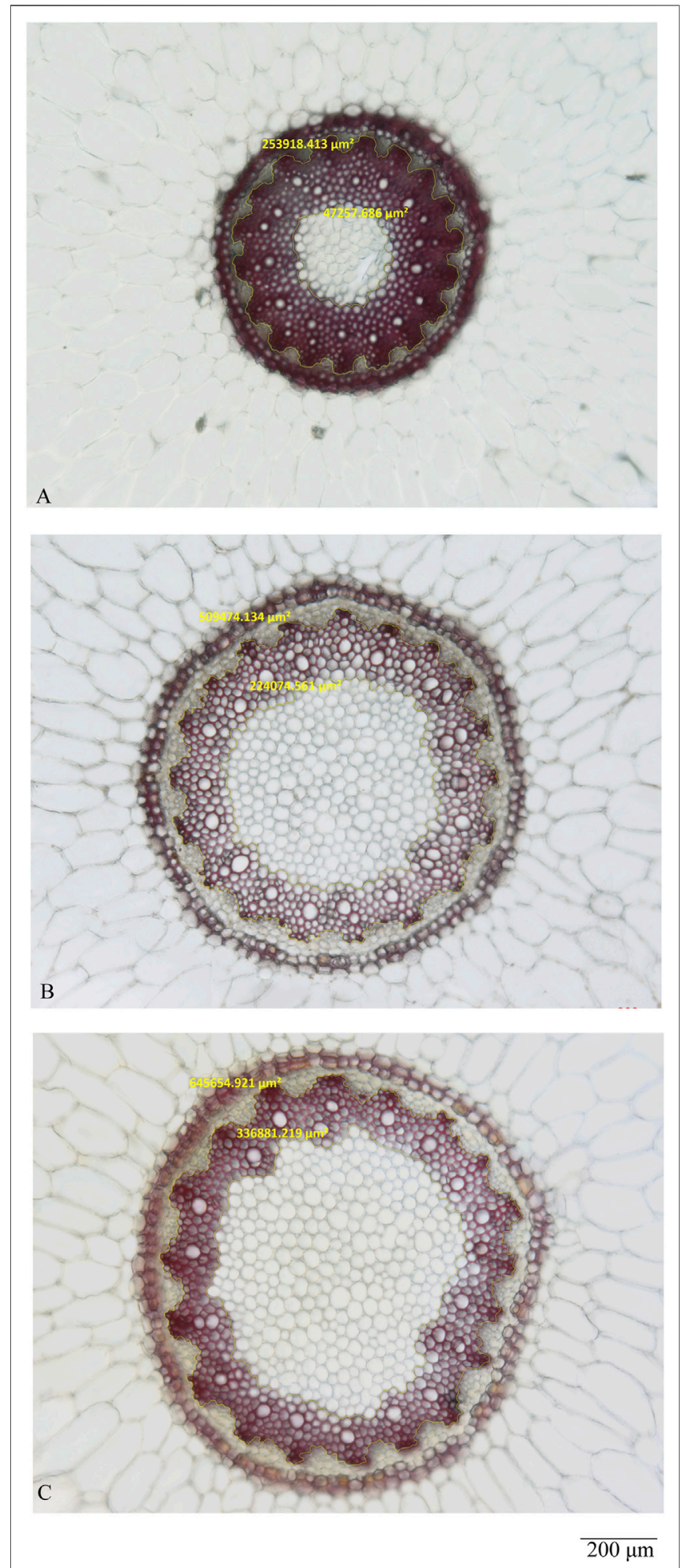

FIGURE 4 | Measurement analysis by ZEN of the middle site: (A) ZheMaidong, (B) Chuan-Maidong, and (C) Chuan-Maidong with paclobutrazol.

for Chuan-Maidong with paclobutrazol. The xylem area ranged from 152,195 to $446,337 \mu \mathrm{m}^{2}$ for Zhe-Maidong, from 232,651 to $446,472 \mu \mathrm{m}^{2}$ for Chuan-Maidong, and from 214,702 to 
TABLE 3 | Measurement data of the three quality grades of Maidong in the middle sampling site.

\begin{tabular}{|c|c|c|c|c|c|c|c|c|c|}
\hline $\begin{array}{l}\text { Sample } \\
\text { no. }\end{array}$ & la & Illb & IIIc & III/Id & $\begin{array}{c}\text { Sample } \\
\text { no. }\end{array}$ & 1 & II & III & III/I \\
\hline $\mathrm{Z} 1-1$ & 81,090 & 358,251 & 277,161 & 3.42 & CP2-1 & 469,260 & 814,575 & 345,315 & 0.74 \\
\hline Z1-2 & 47,258 & 253,918 & 206,660 & 4.37 & CP2-2 & 338,453 & 642,992 & 304,539 & 0.90 \\
\hline Z1-3 & 36,115 & 250,914 & 214,799 & 5.95 & CP2-3 & 388,940 & 662,765 & 273,825 & 0.70 \\
\hline Z1-4 & 188,958 & 635,295 & 446,337 & 2.36 & CP2-4 & 518,334 & 858,267 & 339,933 & 0.66 \\
\hline Z2-1 & 170,782 & 512,002 & 341,220 & 2.00 & CP3-1 & 604,054 & 961,707 & 357,653 & 0.59 \\
\hline Z2-2 & 114,201 & 454,009 & 339,808 & 2.98 & CP3-2 & 673,572 & 1,160,622 & 487,050 & 0.72 \\
\hline Z2-3 & 116,845 & 380,068 & 263,223 & 2.25 & CP3-3 & 626,398 & 993,179 & 366,781 & 0.59 \\
\hline Z2-4 & 24,675 & 215,227 & 190,552 & 7.72 & CP3-4 & 917,850 & $1,364,305$ & 446,455 & 0.49 \\
\hline Z3-1 & 157,485 & 470,416 & 312,931 & 2.00 & CP4-1 & 870,824 & $1,253,498$ & 382,674 & 0.44 \\
\hline Z3-2 & 29,963 & 182,158 & 152,195 & 5.08 & CP4-2 & 636,175 & 958,408 & 322,233 & 0.51 \\
\hline Z3-3 & 96,574 & 376,058 & 279,484 & 2.89 & CP4-3 & 540,641 & 865,545 & 324,904 & 0.60 \\
\hline Z3-4 & 107,117 & 392,831 & 285,714 & 2.67 & CP4-4 & 293,372 & 559,209 & 265,837 & 0.91 \\
\hline Z4-1 & 145,391 & 476,613 & 331,222 & 2.28 & CP5-1 & 515,175 & 958,198 & 443,023 & 0.86 \\
\hline Z4-2 & 126,981 & 382,109 & 255,128 & 2.00 & CP5-2 & 341,307 & 592,817 & 251,510 & 0.74 \\
\hline Z4-3 & 165,293 & 496,785 & 331,492 & 2.00 & СР5-3 & 494,032 & 857,986 & 363,954 & 0.74 \\
\hline Z4-4 & 115,890 & 453,956 & 338,066 & 2.92 & CP5-4 & 264,706 & 499,548 & 234,842 & 0.89 \\
\hline C1-1 & 224,075 & 509,474 & 285,399 & 1.27 & CP6-1 & 443,379 & 799,688 & 356,309 & 0.80 \\
\hline C1-2 & 255,424 & 534,656 & 279,232 & 1.10 & CP6-2 & 408,180 & 743,671 & 335,491 & 0.82 \\
\hline C1-3 & 227,877 & 526,606 & 298,729 & 1.31 & CP6-3 & 280,642 & 550,861 & 270,219 & 0.96 \\
\hline C1-4 & 140,699 & 373,350 & 232,651 & 1.65 & CP6-4 & 679,345 & 979,165 & 299,820 & 0.44 \\
\hline C2-1 & 285,660 & 634,466 & 348,806 & 1.22 & CP7-1 & 471,043 & 829,813 & 358,770 & 0.76 \\
\hline C2-2 & 374,893 & 799,515 & 424,622 & 1.13 & CP7-2 & 437,266 & 785,005 & 347,739 & 0.80 \\
\hline C2-3 & 383,775 & 830,247 & 446,472 & 1.16 & CP7-3 & 592,120 & 970,300 & 378,180 & 0.64 \\
\hline C2-4 & 334,601 & 660,323 & 325,722 & 0.97 & CP7-4 & 336,881 & 645,655 & 308,774 & 0.92 \\
\hline C3-1 & 230,592 & 571,813 & 341,221 & 1.48 & CP8-1 & 298,457 & 586,455 & 287,998 & 0.96 \\
\hline C3-2 & 210,726 & 522,545 & 311,819 & 1.48 & CP8-2 & 363,258 & 654,104 & 290,846 & 0.80 \\
\hline C3-3 & 368,176 & 802,156 & 433,980 & 1.18 & CP8-3 & 785,879 & $1,155,160$ & 369,281 & 0.47 \\
\hline C3-4 & 299,166 & 659,963 & 360,797 & 1.21 & CP8-4 & 721,453 & $1,012,287$ & 290,834 & 0.40 \\
\hline C4-1 & 197,351 & 460,312 & 262,961 & 1.33 & CP9-1 & 769,307 & $1,174,854$ & 405,547 & 0.53 \\
\hline C4-2 & 210,724 & 490,761 & 280,037 & 1.33 & CP9-2 & 746,678 & $1,166,125$ & 419,447 & 0.56 \\
\hline C4-3 & 160,184 & 421,191 & 261,007 & 1.63 & CP9-3 & 978,576 & $1,374,474$ & 395,898 & 0.40 \\
\hline C4-4 & 258,882 & 532,082 & 273,200 & 1.06 & CP9-4 & $1,114,243$ & $1,606,081$ & 491,838 & 0.44 \\
\hline CP1-1 & 583,132 & $1,005,278$ & 422,146 & 0.72 & CP10-1 & 465,625 & 802,405 & 336,780 & 0.72 \\
\hline CP1-2 & 951,800 & $1,665,864$ & 714,064 & 0.75 & CP10-2 & 525,828 & 933,723 & 407,895 & 0.78 \\
\hline CP1-3 & 329,114 & 543,816 & 214,702 & 0.65 & CP10-3 & 387,022 & 674,291 & 287,269 & 0.74 \\
\hline CP1-4 & 450,713 & 750,615 & 299,902 & 0.66 & CP10-4 & 320,777 & 584,877 & 264,100 & 0.82 \\
\hline
\end{tabular}

${ }^{a}$ The area of pith.

${ }^{b}$ The area of xylem plus pith.

${ }^{c}$ The area of xylem (II minus I).

${ }^{d}$ The area ratio between xylem and pith.

$714,064 \mu \mathrm{m}^{2}$ for Chuan-Maidong with paclobutrazol. The range of the area ratio between xylem and pith was as follows: 2.00-7.72 for Zhe-Maidong, 0.97-1.65 for Chuan-Maidong, and 0.40-0.96 for Chuan-Maidong with paclobutrazol.

After factoring in the area ratio of each sample, the mean and standard deviation (SD) of the three grades of Maidong were calculated (Table 4). A chart was generated to show the relationship of the area ratio between xylem with the pith and three quality grades of Maidong. According to these numeric values, the chart indicates a method by which the three grades of Maidong could be quickly and efficiently distinguished by the area ratio between xylem and pith (Figure 5).

Variance analysis of the area ratio between xylem and pith of the three quality grades of Maidong was performed with SPSS $(\mathrm{F}=62.842, p<0.001)$. Results show a highly significant difference between Zhe-Maidong and Chuan-Maidong and Zhe-Maidong and Chuan-Maidong with paclobutrazol (both
TABLE 4 | Mean and SD of the area ratio between xylem and pith of each grades.

Maidong

Area ratio between xylem and pith

Zhe-Maidong

Chuan-Maidong

$3.306 \pm 1.663($ mean $\pm S D, n=16)$

Chuan-Maidong with paclobutrazol

$1.282 \pm 0.196($ mean $\pm S D, n=16)$

$0.691 \pm 0.161($ mean $\pm S D, n=40)$

$p<0.001)$ and a significant difference between ChuanMaidong and Chuan-Maidong with paclobutrazol $(p=0.041)$.

\section{Evaluation Maidong in Herbal Markets and Botanical Pharmacies}

Twelve batches of Maidong obtained from Chinese herbal markets and botanical pharmacies were analyzed. All samples 


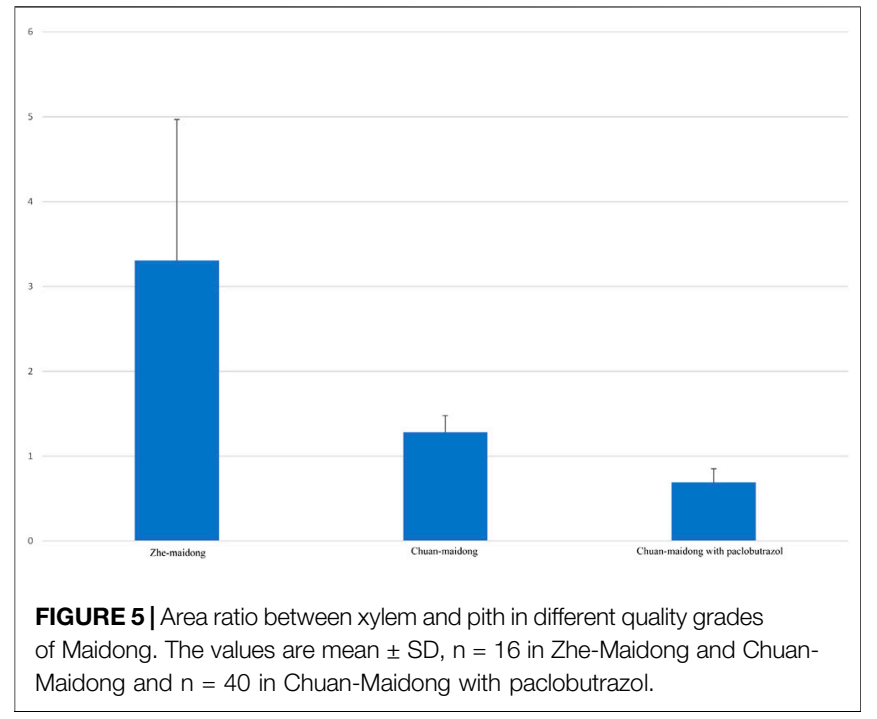

were crude drugs without cultivation information. Results showed that the area ratio between xylem and pith of all samples ranged 0.41-1.06 (Table 5).

Moreover, the area ratio between xylem and pith was pairwise compared between Maidong in the market and three grades of Maidong with SPSS: Maidong in the market vs. ZheMaidong $(p<0.001)$, Maidong in the market vs. ChuanMaidong $(p<0.001)$, and Maidong in the market vs. Chuan-
Maidong with paclobutrazol $(p=0.915)$. Data of the market samples were not significantly different from those of ChuanMaidong with paclobutrazol. Therefore, it was deduced that all the samples from the market were Chuan-Maidong with paclobutrazol.

\section{Method Validation by LC/MS}

To validate the accuracy of the method to distinguish the three quality grades of Maidong based on microscopic quantification, the market samples were tested by LC/MS. Qualitative analysis of paclobutrazol was conducted using the multiple reaction monitoring mode, in which monitoring of precursor ion to product ion transitions of $\mathrm{m} / \mathrm{z} 294 \rightarrow \mathrm{m} / \mathrm{z} 70$ and $\mathrm{m} / \mathrm{z} 125$ for paclobutrazol was performed. The MS spectra of the analytes are shown in Figure 6. Results revealed that the twelve batches of Maidong from the herbal markets and botanical pharmacies had the same ion chromatograms as those of paclobutrazol standard solutions, thereby confirming that Maidong samples from the market were Chuan-Maidong with paclobutrazol. The LC/MS findings proved the accuracy of microscopic quantification in identifying the quality grades of Maidong.

\section{Method Extension}

This study established an analytical method to identify and evaluate three quality grades of Maidong using the ZEISS microscope and ZEN software. The critical quantification information is the area ratio between xylem and pith. The ratio is a relative rather than an absolute value.

\begin{tabular}{|c|c|c|c|c|c|c|c|c|c|}
\hline $\begin{array}{l}\text { Sample } \\
\text { no. }\end{array}$ & $\rho^{a}$ & Ilb & IIIC & III/Id & $\begin{array}{c}\text { Sample } \\
\text { no. }\end{array}$ & 1 & II & III & III/I \\
\hline MS1-1 & 761,648 & $1,160,868$ & 399,220 & 0.52 & MS7-1 & 367,018 & 584,475 & 217,457 & 0.59 \\
\hline MS1-2 & 349,188 & 568,929 & 219,741 & 0.63 & MS7-2 & 493,800 & 766,032 & 272,232 & 0.55 \\
\hline MS1-3 & 420,024 & 751,610 & 331,586 & 0.79 & MS7-3 & 406,414 & 679,591 & 273,177 & 0.67 \\
\hline MS1-4 & $1,172,162$ & $1,650,899$ & 478,737 & 0.41 & MS7-4 & 698,200 & $1,117,552$ & 214,176 & 0.61 \\
\hline MS2-1 & 501,344 & 786,097 & 284,753 & 0.57 & MS8-1 & 419,892 & 653,733 & 233,841 & 0.56 \\
\hline MS2-2 & 335,461 & 595,213 & 259,752 & 0.77 & MS8-2 & 431,640 & 764,408 & 332,768 & 0.77 \\
\hline MS2-3 & 497,161 & 826,628 & 329,467 & 0.66 & MS8-3 & 714,762 & $1,349,919$ & 635,157 & 0.89 \\
\hline MS2-4 & 408,744 & 695,316 & 286,572 & 0.70 & MS8-4 & 424,400 & 741,024 & 316,624 & 0.75 \\
\hline MS3-1 & 852,114 & $1,300,519$ & 448,405 & 0.53 & MS9-1 & 660,896 & $1,052,320$ & 391,424 & 0.59 \\
\hline MS3-2 & 364,316 & 623,910 & 259,594 & 0.71 & MS9-2 & 510,832 & 774,384 & 263,552 & 0.52 \\
\hline MS3-3 & 341,386 & 556,751 & 215,365 & 0.63 & MS9-3 & 482,832 & 712,928 & 230,096 & 0.48 \\
\hline MS3-4 & 335,953 & 644,354 & 308,401 & 0.92 & MS9-4 & 342,560 & 634,768 & 292,208 & 0.85 \\
\hline MS4-1 & 272,036 & 493,928 & 221,892 & 0.82 & MS10-1 & 834,652 & $1,360,482$ & 525,830 & 0.63 \\
\hline MS4-2 & 568,621 & 948,040 & 379,419 & 0.67 & MS10-2 & 675,437 & $1,154,997$ & 479,560 & 0.71 \\
\hline MS4-3 & 488,984 & 728,193 & 239,209 & 0.49 & MS10-3 & 413,458 & 748,358 & 334,900 & 0.81 \\
\hline MS4-4 & 333,198 & 630,627 & 297,429 & 0.89 & MS10-4 & 365,905 & 684,242 & 318,337 & 0.87 \\
\hline MS5-1 & 456,148 & 743,759 & 287,611 & 0.63 & MS11-1 & 254,019 & 497,877 & 243,858 & 0.96 \\
\hline MS5-2 & 435,293 & 679,153 & 243,860 & 0.56 & MS11-2 & 453,317 & 788,771 & 335,454 & 0.74 \\
\hline MS5-3 & 313,637 & 555,578 & 241,941 & 0.77 & MS11-3 & 543,809 & 919,037 & 375,228 & 0.69 \\
\hline MS5-4 & 147,068 & 304,076 & 157,008 & 1.07 & MS11-4 & 379,567 & 713,586 & 334,018 & 0.88 \\
\hline MS6-1 & 258,416 & 490,179 & 231,763 & 0.90 & MS12-1 & 756,490 & $1,202,819$ & 446,329 & 0.59 \\
\hline MS6-2 & 365,085 & 592,346 & 227,261 & 0.62 & MS12-2 & 694,456 & $1,159,741$ & 465,285 & 0.67 \\
\hline MS6-3 & 430,287 & 687,642 & 257,355 & 0.60 & MS12-3 & 574,239 & 970,463 & 396,224 & 0.69 \\
\hline MS6-4 & 244,198 & 479,189 & 234,991 & 0.96 & MS12-4 & 338,910 & 647,318 & 308,408 & 0.91 \\
\hline
\end{tabular}

${ }^{a}$ The area of pith.

${ }^{b}$ The area of xylem plus pith.

${ }^{c}$ The area of xylem (II minus I).

${ }^{d}$ The area ratio between xylem and pith. 


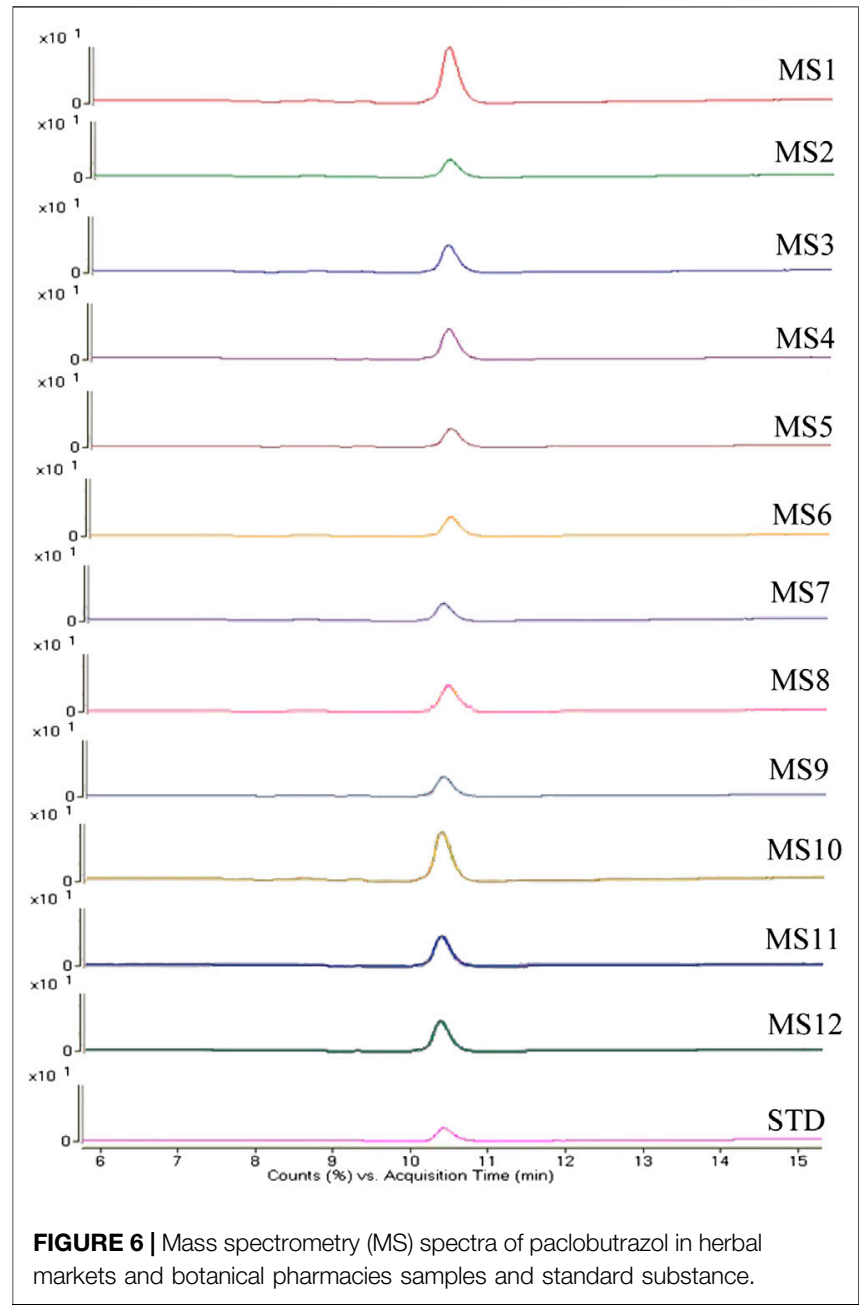

In theory, if image software could indicate information such as pixels of a selected area, then the pixel ratio should be equal to the area ratio and thus could be used to identify three quality grades of Maidong.

To verify this assumption, this study selected a section of Maidong randomly from market samples and acquired an image of the stele using an OLYMPUS microscope; thereafter, the image was analyzed this picture with the commonly used image processing software Photoshop CS2 (Adobe, CA). The pith and xylem areas were selected separately using a polygonal lasso tool. The pixel of the selected area was shown in a histogram, and the pixel ratio between xylem and pith was calculated. Results showed that the pixel ratio between xylem and pith was equal to the area ratio between xylem and pith (Figure 7, Table 6).

The quantification data are based on a relative value; thus, the method could be used to distinguish three grades of Maidong without the constraints associated with the type of themicroscope and processing software.

\section{DISCUSSION}

In this study, we evaluated the microscopic characteristics of Maidong from three quality grades; the result showed the pith
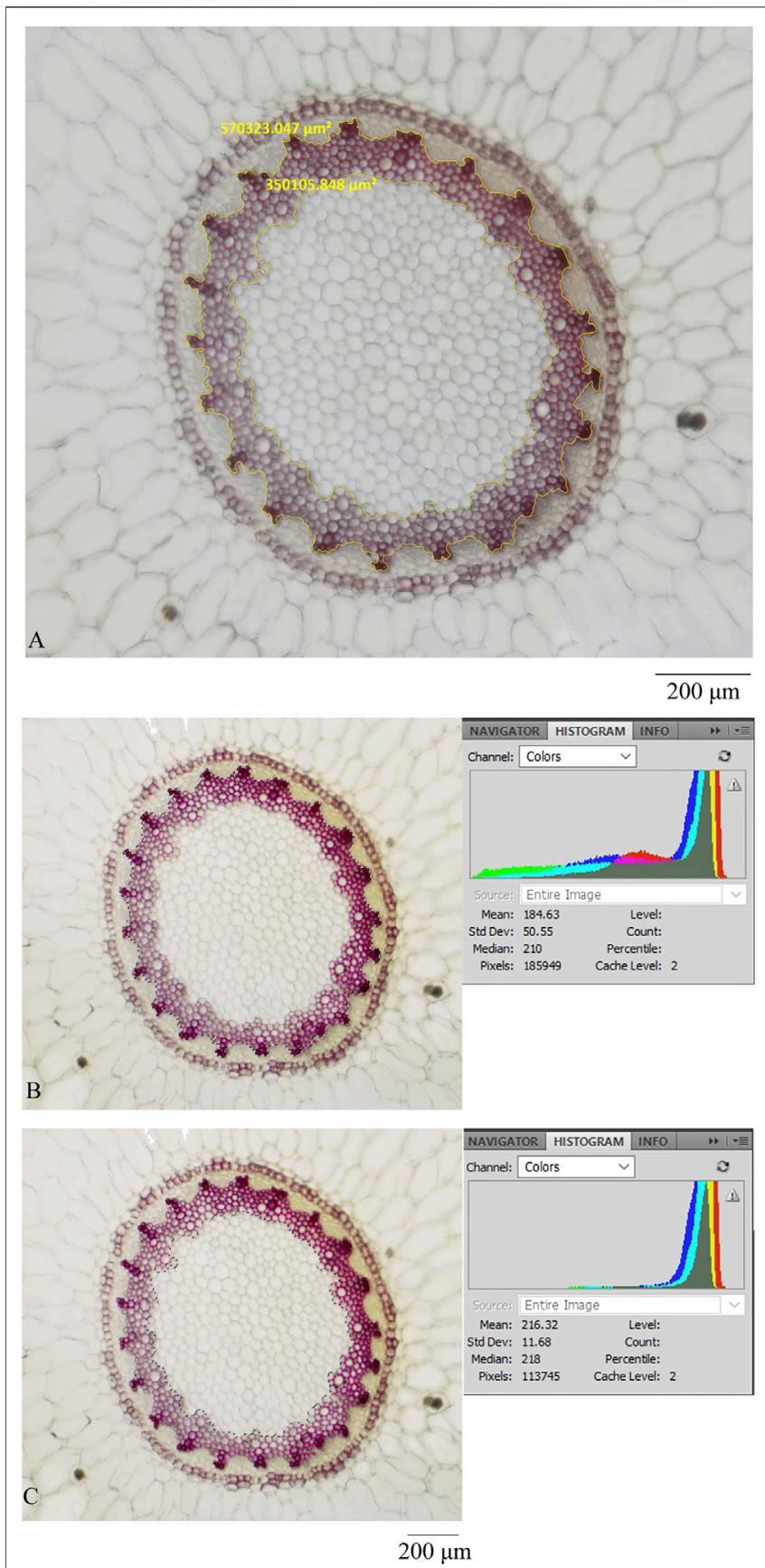

FIGURE 7|Transverse section was processed by different microscopes and software: (A) ZEISS and ZEN, (B) OLYMPUS and photoshop (showing the pixel of xylem and pith), and (C) OLYMPUS and photoshop (showing the pixel of pith).

and xylem area in the middle sampling site, the thickness and lignification of endodermis and stone cells, and the shape of the protoxylem and lignified degree in the lower sampling site different among the three quality grades of Maidong. Our findings reveal that cultivation age, area, and especially plant growth regulator could influence the anatomical characteristics of Maidong. The area ratio between xylem and pith, which is an 
TABLE 6 | Measurement data by different microscopes and software.

\begin{tabular}{lcccc}
\hline Microscope+software & Pith & Pith+xylem & Xylem & $\begin{array}{c}\text { Xylem/ } \\
\text { pith }\end{array}$ \\
\hline ZEISS+ZEN & $350,106 \mu \mathrm{m}^{2}$ & $570,323 \mu \mathrm{m}^{2}$ & $220,218 \mu \mathrm{m}^{2}$ & 0.63 \\
OLYMPUS+photoshop & 113,745 & 185,949 & 73,133 pixel & 0.63 \\
& pixel & pixel & & \\
\hline
\end{tabular}

objective and practical microscopic characteristic, was first developed to distinguish the different quality grades of Maidong; the area ratio varied according to the quality grades as follows: Zhe-Maidong, $3.306 \pm 1.663$ (mean $\pm \mathrm{SD}, \mathrm{n}=16$ ); Chuan-Maidong, $1.282 \pm 0.196$ (mean $\pm \mathrm{SD}, \mathrm{n}=16$ ); and ChuanMaidong with paclobutrazol, $0.691 \pm 0.161$ (mean $\pm S D, n=40)$. Consequently, a novel microscopic quantification method to distinguish the three quality grades of Maidong was established.

The identification of three quality grades of Ophiopogonis Radix will make efforts on three aspects: the recovery of superior germplasm resource of Zhe-Maidong, provide evidence to customers and herbalists who want better quality of Maidong, and the improvement quality of Maidong in market and botanical pharmacies. Our study is the first to apply microscopic techniques to test and distinguish Ophiopogonis Radix from different regions and with different cultivation modes simultaneously. It is also the first to use that microscopic quantitative method to classify the quality grades of herbal medicine. This research largely expanded the application range of microscopic technology and provided another way to evaluate the quality grades of herbal medicine.

Microscopic quantification avoids subjective and relative factors in microscope research. Generally, quantification of microscopic characteristics is influenced by sampling site; thus, in most cases, the diameter of the sampling site should be restricted in microscopic quantification analysis, which limits the practical application of this method. For example, the identification of Wuzhimaotao (Radix Fici Hirtae) by quantification used samples around $1 \mathrm{~cm}$ in diameter (Au et al., 2009). In our research, the sampling site was considered and investigated. Results showed that the microscopic quantification of the middle sampling site of three quality grades of Maidong is stable, consistent and subject to quantification, and reveals important distinctions. Maidong is a fusiform tuber, and the middle location is easily determined; hence, there is no need to restrict the diameter of sampling site. The practicability of this method could be improved.

\section{REFERENCES}

Au, D. T., Chen, H., Jiang, Z., and Zhao, Z. (2009). A novel method to identify the Chinese herbal medicine Wuzhimaotao by quantification of laticifers. Microsc. Res. Tech. 72, 293-298. doi:10.1002/jemt.20650

Chen, M. H., Chen, X. J., Wang, M., Lin, L. G., and Wang, Y. T. (2016). Ophiopogon japonicus-A phytochemical, ethnomedicinal and pharmacological review. J. Ethnopharmacol. 181, 193-213. doi:10.1016/j.jep. 2016.01.037

Chen, X., Jin, J., Tang, J., Wang, Z., Wang, J., Jin, L., et al. (2011). Extraction, purification, characterization and hypoglycemic activity of a polysaccharide
Currently, not all microscopes equipped with software can measure actual areas; thus, measurement of actual areas is limited to several types of microscopes and software. In this study, the identification characteristic is based on a ratio, which is a relative value. In theory and in practice, microscopic images from any type of the microscope could be processed using normal image processing software to obtain the pixel value of selected areas. The pixel ratio is equal to the area ratio, which means that our novel method is not limited by the type of the microscope and software, thereby further expanding the scope of application.

For Chuan-Maidong with paclobutrazol, the microscopic characteristics of lower sampling site were not stable, and almost half of samples have undeveloped metaxylem. We assumed that was resulted of short cultivation age and the influence of plant growth regulator. We will confirm this hypothesis in the future studies.

In conclusion, we established an efficient, convenient, and practical method evaluating the quality grades of Maidong based on microscopic quantification, which could in turn improve the quality and safety of Maidong in China, specifically. Furthermore, our study also expands the application of quantitative microscopic techniques and provides another way to identify the quality grades of herbal medicine.

\section{DATA AVAILABILITY STATEMENT}

The raw data supporting the conclusions of this article will be made available by the authors, without undue reservation.

\section{AUTHOR CONTRIBUTIONS}

KY conceived and designed the study, did literature research, and prepared the manuscript; WL collected LC-MS data; NZ did the statistical analysis; XC did the data acquisition; SZ collected the plant material; TZ edited the manuscript; SK identified the plant material; FW and SM guaranteed integrity of the entire study and reviewed the manuscript.

\section{ACKNOWLEDGMENTS}

The authors would like to thank Bo Tang, Zhuo Jin, Guojian Zhu, and Haobin $\mathrm{Hu}$ for the sample collection.

isolated from the root of ophiopogon japonicus. Carbohydr. Polym. 83, 749-754. doi:10.1016/j.carbpol.2010.08.050

Kang, T., Feng, X., Yuan, D., Ohba, K., and Tanaka, T. (2012). Microscopic identification of the remnant hair or feather of five animal drug components in Shenrongbian pill. Acta Pharm. Sin. B 2, 306-311. doi:10.1016/j.apsb.2012. 03.008

Kou, J., Sun, Y., Lin, Y., Cheng, Z., Zheng, W., Yu, B., et al. (2005a). Antiinflammatory activities of aqueous extract from radix ophiopogon japonicus and its two constituents. Biol. Pharm. Bull. 28, 1234-1238. doi:10.1248/bpb.28. 1234

Kou, J., Yu, B., and Xu, Q. (2005b). Inhibitory effects of ethanol extract from radix ophiopogon japonicus on venous thrombosis linked with its 
endothelium-protective and anti-adhesive activities. Vasc. Pharmacol. 43, 157-163. doi:10.1016/j.vph.2005.06.004

Li, X. E., Wang, Y. X., Sun, P., and Liao, D. Q. (2016a). Determination of saponin content in Hang Maidong and Chuan Maidong via HPLC-ELSD analysis. J. Anal. Methods Chem. 2016, 7214607-7214615. doi:10.1155/2016/7214607

Li, Z., Chen, Y., Ma, L. K., Zhu, M., and Jiang, H. L. (2016b). Establish and discuss the quality standard of ophiopogonis radix from Zhejiang province. Chin. J. Modern Appl. Pharm. 33, 795-799. doi:10.13748/j.cnki.issn1007-7693.2016. 06.030

Lin, W. L., Su, W. W., Cai, X. Y., Luo, L. K., Li, P. B., and Wang, Y. G. (2011). Fermentation effects of oligosaccharides of radix ophiopogonis on alloxaninduced diabetes in mice. Int. J. Biol. Macromol. 49, 194-200. doi:10.1016/j. ijbiomac.2011.04.011

Liu, H.-j., Hu, H.-b., Chu, C., Li, Q., and Li, P. (2011). Morphological and microscopic identification studies of cordyceps and its counterfeits. Acta Pharm. Sin. B 1, 189-195. doi:10.1016/j.apsb.2011.06.013

Lu, X., Tong, W., Wang, S., Li, J., Zheng, J., Fan, X., et al. (2017). Comparison of the chemical consituents and immunomodulatory activity of ophiopogonis radix from two different producing areas. J. Pharmaceut. Biomed. Anal. 134, 60-70. doi:10.1016/j.jpba.2016.11.025

Mo, J. X. (2010). Comparative research of ophipogon japonicus and its adulteration in market. J. Chin. Med. Mater. 33, 1074-1076. doi:10.13863/j.issn1001-4454. 2010.07.021

Nguyen, T. H. A., Tran, V. S., Andrea, P., Katrin, F., and Ludger, A. W. (2003). Homoisoflavonoids from ophiopogon japonicus Ker-Gawler. Phytochemistry 62, 1153-1158. doi:10.1016/S0031-9422(02)00515-0

Shen, Z. G., Chauser-Volfson, E., Gutterman, Y., and Hu, Z. H. (2001). Anatomy, histochemistry and phytochemistry of leaves in Aloe vera var. chinensis. Acta Bot. Sin. 43, 780-787. doi:10.1614/0043-1745(2001)049[0694:WOACCT]2.0. $\mathrm{CO} ; 2$

The State Pharmacopoeia Committee of China (2020). Pharmacopoeia of the People's Republic of China. Beijing, China: China Medical Science Press, Vol. $1162,851-852$.

Xiong, S. L., Li, A., Huang, N., Lu, F., and Hou, D. (2011). Antioxidant and immunoregulatory activity of different polysaccharide fractions from tuber of ophiopogon japonicus. Carbohydr. Polym. 86, 1273-1280. doi:10.1016/j. carbpol.2011.06.025

Xu, Y., Song, W., Zhou, P., Li, P., and Li, H. (2015). Morphological and microscopic characterization of five commonly-used testacean traditional Chinese medicines. Acta Pharm. Sin. B 5, 358-366. doi:10.1016/j.apsb.2015.03.014

Yu, K. Z., Yan, H., Tai, H. C., Zhang, N. P., Cheng, X. L., Guo, Z. X., et al. (2017). Distinguishing the Chinese materia medica Tiepishihu from similar Dendrobium species of the same genus using histological and microscopic method. Microsc. Res. Tech. 80, 745-755. doi:10.1002/jemt.22860

Zhang, J., Fan, S., Mao, Y., Ji, Y., Jin, L., Lu, J., et al. (2016). Cardiovascular protective effect of polysaccharide from ophiopogon japonicus in diabetic rats. Int. J. Biol. Macromol. 82, 505-513. doi:10.1016/j.ijbiomac.2015.09.069

Zhang, L., Luo, Z., Cui, S., Xie, L., Yu, J., Tang, D., et al. (2019). Residue of paclobutrazol and its regulatory effects on the secondary metabolites of ophiopogon japonicas. Molecules 24, 3504-3520. doi:10.3390/molecules24193504

Zhang, T., Kang, L. P., Yu, H. S., Liu, Y. X., Zhao, Y., Xiong, C. Q., et al. (2012). Steroidal saponins from the tuber of ophiopogon japonicus. Steroids 77, 1298-1305. doi:10.1016/j.steroids.2012.04.015

Zhao, Z., Guo, P., and Brand, E. (2012). The formation of daodi medicinal materials. J. Ethnopharmacol. 140, 476-481. doi:10.1016/j.jep.2012.01.048

Zhao, Z., Hu, Y., Liang, Z., Yuen, J. P., Jiang, Z., and Leung, K. S. (2006). Authentication is fundamental for standardization of Chinese medicines. Planta. Med. 72, 865-874. doi:10.1055/s-2006-947209

Conflict of Interest: The authors declare that the research was conducted in the absence of any commercial or financial relationships that could be construed as a potential conflict of interest.

Copyright $\odot 2021$ Yu, Liu, Zhang, Cheng, Zhou, Zuo, Kang, Wei and Ma. This is an open-access article distributed under the terms of the Creative Commons Attribution License (CC BY). The use, distribution or reproduction in other forums is permitted, provided the original author $(s)$ and the copyright owner(s) are credited and that the original publication in this journal is cited, in accordance with accepted academic practice. No use, distribution or reproduction is permitted which does not comply with these terms. 